\title{
Junior Scientific Masterclass. Groningse professionele kweekvijver om studenten tot artsonderzoeker op te leiden
}

\author{
M.H.W. Hooiveld • J.C. Kluin-Nelemans • M.H. \\ W. Hooiveld • J.C. Kluin-Nelemans • J.C. Kluin- \\ Nelemans
}

Samenvatting De Junior Scientific Masterclass (JSM) biedt gemotiveerde studenten extra mogelijkheden om binnen de studie geneeskunde en tandheelkunde wetenschappelijk onderzoek te doen. De JSM wil binnen het Universitair Medisch Centrum Groningen (UMCG) een kweekvijver zijn voor (tand)artsen, die later patiëntenzorg willen combineren met wetenschappelijk onderzoek. Een speciaal opleidingsprogramma stelt de studenten in staat om in de bacheloropleiding een 'Honours'-graad voor onderzoek te behalen en/of gecombineerd met hun coassistentschappen in de masterfase een promotietraject te doorlopen dat leidt tot een MD én PhD. Het 'Honours'-traject bekwaamt studenten in basaal wetenschappelijke vaardigheden. Het programma bestaat uit een scala aan cursussen en activiteiten, waaronder het uitvoeren van een wetenschappelijk proefproject. Studenten, die het 'Honours'-traject van 30 ECs (European Credit Transfer System) succesvol doorlopen (bovenop de reguliere 180 ECs), verwerven de aantekening 'Honours' op de bachelorbul.

Binnen het $\mathrm{MD} / \mathrm{PhD}$-traject kunnen studenten de laatste twee jaren van de masterfase combineren met een promotieonderzoek. Dit kan dankzij een additionele, gefinancierde onderzoeksperiode van twee jaar met als doel zowel het artsexamen als het promotietraject (tegelijkertijd) succesvol af te ronden. Dit artikel geeft een overzicht van de resultaten van de eerste acht jaren van het JSM-programma dat geresulteerd heeft in de verwezenlijking van een 'Honours'-opleidingstraject. (Hooiveld MHW, Kluin-Nelemans JC. Junior Scientific Masterclass. Groningse professionele kweekvijver om studenten tot artsonderzoeker op te leiden. Tijdschrift voor Medisch Onderwijs 2007;26 (6):288-296.)

\section{Inleiding}

Het is moeilijk om posities binnen het medisch- wetenschappelijk onderzoek in te vullen. ${ }^{1-3}$ Ook binnen het Universitair Medisch Centrum Groningen (UMCG) maakt men zich al langere tijd zorgen over de geringe interesse van artsen voor een academische carrière. Om onder studenten de belangstelling voor medisch-wetenschappelijk onderzoek aan te wakkeren heeft het UMCG, op initiatief van prof. dr. T.H. The, in 1999 de Junior Scientific Masterclass (JSM) opgericht. The wilde voor studenten geneeskunde en tandheelkunde met interesse voor wetenschappelijk onderzoek naast de reguliere studie tot arts (MD, 'Doctor of Medicine') of tandarts (DMD, 'Doctor of Dental Medicine') extra mogelijkheden creëren in de vorm van een additioneel wetenschappelijk opleidingstraject. De JSM is voorzichtig gestart met enkele cursussen. Het programma heeft de afgelopen jaren echter een stormachtige ontwikkeling doorgemaakt en is uitgegroeid tot een professionele opleiding. Het in een vroeg stadium kweken van interesse en aanbieden van kansen zal ertoe leiden dat studenten zich vanaf het begin van de studie gaan bekwamen in het doen van wetenschappelijk onderzoek om vervolgens in een vroeg stadium te starten met een promotie-onderzoek. Dit zal de kans vergroten op een succesvolle carrière tot academisch arts/specialist.

Het JSM programma bestaat acht jaar. Reden voor een terugblik, een beschouwing én een vooruitblik.

\section{Een terugblik...}

Het JSM-programma kenmerkt zich vanaf haar start in 1999 door drie belangrijke pijlers, namelijk: 
1. een gevarieerd cursusaanbod, geëvolueerd tot het Bachelor 'Honours'-traject

2. de proefprojecten

3. het $\mathrm{MD} / \mathrm{PhD}$-traject

Sinds 1999 hebben meer dan 300 studenten deelgenomen aan één of meerdere JSM-activiteiten.

\section{Een gevarieerd cursusaanbod}

Vanaf de start van de studie biedt de JSM studenten extra mogelijkheden om zich bezig te houden met wetenschappelijk onderzoek, waarbij zoveel mogelijk verschillende aspecten van de uitvoering worden belicht en aangeboden (zie box 1). Met een groot deel van de cursussen is inmiddels veel ervaring opgedaan. Hieronder volgt een korte beschrijving van de cursussen.

\section{Cursussen Wetenschapsmethodologie}

De 'Labcursus' (4 ECs, max. 20 tweedejaars studenten) traint studenten in een aantal medisch-biologische onderzoekstechnieken die ze kunnen toepassen binnen hun eigen onderzoeksproject. Via een 'BBB-benadering' ('Bed to Bench and Back') maken studenten kennis met biomedische wetenschapsmethodologie (modellen) in theorie en praktijk. Het werken in kleine groepjes wordt afgewisseld met plenaire sessies. Sinds 1999 hebben 140 studenten deelgenomen aan deze cursus.

De cursus 'Patient-related Research' (4 ECs, max. 20 tweedejaars studenten) richt zich op de praktijk van patiëntgerelateerd onderzoek. De cursus is sterk interactief en kleinschalig en geeft door middel van veel uit te voeren opdrachten goed inzicht in het brede scala aan onderzoeksmethoden en -technieken binnen dit vakgebied. Sinds de invoering in 2005 hebben in totaal 30 studenten deelgenomen aan deze cursus.

\section{Dé Cursusweek, Schiermonnikoog}

De populairste en langstlopende cursus van de JSM is Dé Cursusweek (4 ECs). Deze cursus, waarbij maximaal 20 studenten aan het eind van hun tweede studiejaar een week diepgaand onderwijs krijgen in wetenschapstechnieken, vindt plaats in een kampeerboerderij op Schiermonnikoog. De cursus kenmerkt zich door een zeer intensief programma (vijf cursusdagen en avonden) en een hoge docentinspanning (gemiddeld vijf tot zes docenten, allen ervaren onderzoekers, deels clinici). Gedurende de cursus schrijven studenten abstracts, maken posters, leren en voeren statistische analyses uit, houden diverse presentaties en doorlopen het gehele proces van het schrijven van een projectaanvraag, inclusief hoor en wederhoor. Na de cursus worden de studenten één jaar begeleid via mentorbijeenkomsten. Sinds 1999 hebben 193 studenten deelgenomen aan deze cursus. Gezien de belangstelling voor en de zwaarte van de cursus doorlopen de studenten een sollicitatieprocedure.

\section{Scientific Writing Course}

In de Scientific Writing Course (2 ECs) voor derdejaars bachelor- en masterstudenten worden studenten getraind in het schrijven en publiceren van wetenschappelijk onderzoek. Tijdens deze cursus, die volledig in het Engels wordt gegeven, komen alle technische aspecten van het schrijven van wetenschappelijke artikelen en abstracts voor congrespresentaties aan bod. Van studenten wordt veel schrijfwerk verwacht en er vindt intensieve, persoonlijke feedback plaats. De cursus is opgebouwd uit één week met plenaire sessies en tijd voor het uitwerken van individuele opdrachten. In de tweede week dienen studenten hun uitgewerkte opdrachten digitaal in te leveren.

Van gevarieerd cursusaanbod tot bachelor 'Honours'traject

De JSM heeft sinds haar start in 1999 veel ervaring opgedaan met het aanleren van onderzoeksvaardigheden aan studenten. Om een 'Honours'-traject mogelijk te maken werd het cursusaanbod uitgebreid en per onderdeel een toetsbare evaluatie toegevoegd. In september 2006 is het 'Honours'- traject (zie box 1) officieel van start gegaan en kunnen studenten geneeskunde door het volgen van onderdelen uit het 'Honours'- traject studiepunten verwerven. Studenten die binnen het 'Honours'traject 30 ECs of meer behalen bovenop hun reguliere 180 ECs worden beloond met de vermelding 'Honours' op de bachelorbul. Hieronder volgt een toelichting.

Binnen het reguliere curriculum krijgen studenten geneeskunde (meer dan voorheen) onderwijs in wetenschappelijk onderzoek. Dit krijgt ondermeer inhoud tijdens de zogenaamde mentorgroepbijeenkomsten, die in elk studiejaar van de bachelorfase (B1 t/m B3) plaatsvinden. Voor geïnteresseerde studenten worden speciale JSM Mentorgroepen georganiseerd, waarbij naast de reguliere opdracht een additionele, individuele opdracht wordt uitgevoerd. In B2 worden Science Electives ingevoerd, die bestaan uit verschillende cursussen, waarbij studenten binnen de eigen interessesfeer kennis kunnen maken met een specifiek vakgebied (o.a. Pathologie, Neurologie, Medische Genetica en Celbiologie) en actief kunnen participeren in het lopende onderzoek. In B3 worden Cursussen op maat georganiseerd die een student, die al betrokken is bij onderzoek, mogelijkheden biedt om zich verder te verdiepen in specifieke onderzoeksvaardigheden waaronder: Scientific Writing Course, 
Box 1 JSM Bachelor 'Honours'-traject*

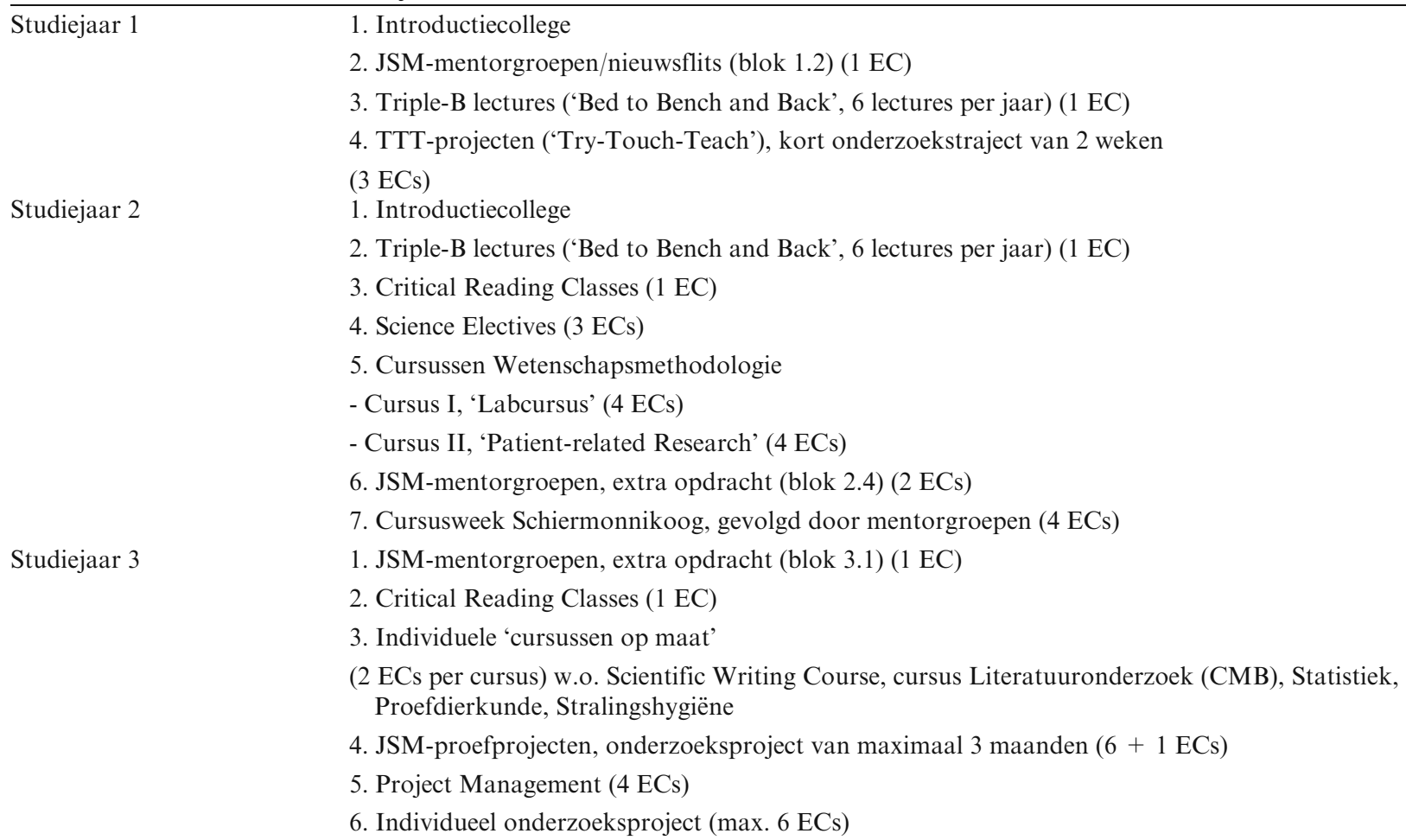

* Om in aanmerking te komen voor de eervolle vermelding 'Honours' dient de studenten minimaal 30 ECs te behalen binnen het JSM Bachelor 'Honours'- traject, waarbij zowel uit de onderdelen van studiejaar 2 als van studiejaar 3 minimaal 10 ECs moeten worden behaald. De bacheloropleiding incl. 'Honours'- traject beslaat in totaal minimaal 210 ECs.

cursus Literatuuronderzoek (Centrale Medische Bibliotheek), cursus Proefdierkunde, Stralingshygiëne en Statistiek.

Sinds de start van het 'Honours'-traject hebben in het eerste studiejaar 60 studenten deelgenomen aan de JSMMentorgroepen, 35 studenten een serie van zes zogenaamde 'Triple-B lectures' succesvol afgerond en hebben 16 studenten een aanvraag ingediend voor een kort (twee weken durend) wetenschappelijk onderzoeksproject (TTT-project).

\section{Proefprojecten}

Om de stap naar een eigen onderzoeksproject voor studenten laagdrempelig te maken, kunnen studenten binnen de JSM een Proefproject aanvragen. Tijdens een proefproject kunnen studenten gedurende maximaal drie maanden een onderzoeksproject uitvoeren. Het aspect 'proef' heeft twee kanten: enerzijds kan de student ervaren of het doen van wetenschappelijk onderzoek haar of hem daadwerkelijk aanspreekt en of de onderzoeksgroep, waar het onderzoek wordt uitgevoerd, goed bevalt. En anderzijds kan de onderzoeksgroep gedurende dezelfde periode beoordelen of de student over voldoende potentieel beschikt om eventueel door te groeien in de richting van een promotietraject (waaronder het
$\mathrm{MD} / \mathrm{PhD}$-traject). Om het voor zowel de student als de onderzoeksgroep extra aantrekkelijk te maken, ontvangt de student bij honorering van een project een geringe financiële bijdrage in de vorm van een korte aanstelling als studentassistent en de onderzoeksgroep een kleine bijdrage in de onderzoekskosten. De student rondt het project af met een eindverslag, gevolgd door een nagesprek. De afgelopen jaren (2001-2006) hebben in totaal 109 studenten een proefproject uitgevoerd. In de eerste drie jaren werden gemiddeld 12 projecten per jaar gehonoreerd. In 2006 waren dit er al 32.

\section{$\mathrm{MD} / \mathrm{PhD}$-traject}

Het in 2001 ingevoerde $\mathrm{MD} / \mathrm{PhD}$-traject biedt getalenteerde en gemotiveerde studenten de mogelijkheid om de reguliere studie te combineren met een promotieopleiding. Het flexibele traject beslaat de laatste twee jaren van de masterfase (M2 en M3, coassistentschappen geneeskunde) en een periode van twee jaren wetenschappelijk onderzoek (gefinancierd door het UMCG) en kan op diverse manieren worden doorlopen. Het $\mathrm{MD} /$ $\mathrm{PhDtraject}$ is een attractief, uitdagend en efficiënt programma. Ondanks dat van de studenten een forse, extra inspanning wordt verwacht naast de reguliere studie is de belangstelling groot. 
Het traject kent een strenge selectieprocedure. Studenten dienen voorafgaand aan indiening van hun projectvoorstel aantoonbaar, wetenschappelijk voorwerk te hebben gedaan in de lijn van het toekomstige MD/ PhD-traject (minimaal één ter publicatie aangeboden Engelstalig wetenschappelijk artikel en bruikbaar voor het toekomstige proefschrift). Projectvoorstellen worden beoordeeld door een onafhankelijke, zeskoppige commissie, gevolgd door een slotbeoordeling binnen de Graduate Schools. Een sollicitatiegesprek met de kandidaat vormt onderdeel van de selectieprocedure, waarbij de student naar analogie van de NWO VENIprocedure het projectvoorstel moet toelichten. Veel aandacht wordt besteed aan de motivatie van de kandidaat, de kwaliteit van de onderzoeksgroep, inclusief personele inzet voor de begeleiding van de kandidaat, en de haalbaarheid van het projectvoorstel. Met de eis dat kandidaten minstens één artikel geschreven moeten hebben, wordt een goede uitgangspositie gecreëerd om aan de hoog gegrepen verwachtingen te kunnen voldoen. Deelname aan of het succesvol afronden van het 'Honours'-traject zijn overigens geen voorwaarden voor toelating tot het $\mathrm{MD} /$ PhDtraject. Wel is het zo dat voor het schrijven van een aanvraag deze studenten waarschijnlijk een betere startpositie hebben. Een $\mathrm{MD} / \mathrm{PhD}$-traject kan in principe op elk moment van de studie worden aangevraagd. Soms hebben studenten aan het eind van de bachelorfase (B3) al voldoende voorwerk gedaan om een $\mathrm{MD} / \mathrm{PhD}$-traject aan te vragen, maar de meesten doen dit aan het eind van studiejaar één van de masterfase (M1, deadline 1 juni) of aan het begin van studiejaar M2 (deadline 1 oktober).

Twee jaar extra bovenop de normale studieduur lijkt kort voor het doen van een gedegen promotie-onderzoek. Er zijn echter meerdere redenen waarom studenten dit traject toch succesvol kunnen doorlopen. Velen zien kans om tijdens het derde studiejaar (B3) met het doorlopen van een proefproject een flinke aanzet te leveren tot een eigen promotie-onderzoek. Veel studenten maken gebruik van de mogelijkheid om hun wetenschappelijke stage (regulier ingeroosterd in M3) naar voren te schuiven (M1) als onderdeel van hun voorbereiding op het aanvragen van een $\mathrm{MD} / \mathrm{PhD}$-traject. En tot slot blijken studenten in deze fase van hun leven opvallend vaak tot zeer veel in staat en erg flexibel te zijn. Het is zelden een probleem een deel van het onderzoek in het buitenland uit te voeren (wordt sterk gestimuleerd), en zij worden vaak minder beperkt door een zich ontwikkelend gezinsleven, iets waar artsonderzoekers (voornamelijk vrouwen en inmiddels $70 \%$ van de geneeskundestudenten) tijdens hun specialisatie of daarna steeds meer door belemmerd worden.

Voor de aanstelling als 'MD/PhD-student' zijn twee volledige aanstellingsjaren ( 2 fte's) beschikbaar. Deze aanstellingsjaren mogen over maximaal vier jaar (48 kalendermaanden, duur van de $\mathrm{MD} / \mathrm{PhDaanstelling)}$ worden verdeeld. Het salaris van een $\mathrm{MD} / \mathrm{PhD}$-student is bij een voltijds aanstelling vergelijkbaar met dat van een assistent in opleiding (aio).

De afgelopen vijf jaren (2001-2006) hebben 77 studenten een $\mathrm{MD} / \mathrm{PhD}$-traject gehonoreerd gekregen, waarvan 22 in 2006. Veertien MD/PhD-ers hebben tot nu toe het traject succesvol doorlopen, waarvan 13 binnen de daarvoor gestelde termijn van twee + twee jaren. Het succesvol doorlopen van een $\mathrm{MD} / \mathrm{PhD}$-traject vergroot ongetwijfeld de kans op een opleidingsplaats, op het verkrijgen van post-doc beurzen (voor bijvoorbeeld het Rubicon en VENI-programma) en op een succesvolle carrière als (tand)artsonderzoeker.

\section{Een nadere analyse}

Het JSM-programma bestaat acht jaar en heeft in die korte tijd een eigen, unieke plek veroverd binnen de Medische Wetenschappen. Daar een constructieve inbreng van studenten bij de verdere ontwikkeling van het programma onontbeerlijk is, zijn binnen de programmagroep drie studenten actief. Zij zijn aanwezig bij vergaderingen en geven gevraagd en ongevraagd advies. Studenten hebben niet alleen een belangrijke invloed gehad op de ontwikkeling van het 'Honours'-traject, maar ook op zaken als de PR en het verbeteren van de nieuwe website (www.jsmgroningen.nl).

Om het vinden van een onderzoeksproject of onderzoeksgroep te vergemakkelijken is een online database ontwikkeld (toegankelijk via de JSM-website), waarin een groot aantal onderzoeksprojecten zijn opgeslagen. Via een eenvoudige zoekfunctie (op 'vakgebied' en 'trefwoord') kunnen studenten snel zoeken naar onderzoeksprojecten binnen de eigen interessesfeer. Even gemakkelijk kunnen onderzoekers via een eenvoudige module voor studenten geschikte projecten aanbieden op dezelfde website.

De kosten van het JSM programma zijn vooralsnog bescheiden. De programmagroep is samengesteld uit een voorzitter ( $0.3 \mathrm{fte})$, beleidsmedewerker ( $1 \mathrm{fte})$, secretariaatsmedewerker ( $0.8 \mathrm{fte})$, vijf stafleden/ onderzoekers (van wie alleen de onderwijsinspanning wordt gehonoreerd op uurbasis) en drie studenten $(0.1 \mathrm{fte}$, studentassistentschap). De programmagroep is verantwoordelijk voor de ontwikkeling van het onderwijsprogramma en de organisatie van cursussen en activiteiten. Het UMCG stelt hiervoor een budget beschikbaar. De JSM rekruteert de vele docenten, mentoren, cursusbegeleiders en ondersteunend personeel, waarbij de inzet van deze docenten sinds 2006 wordt erkend als een reguliere 
onderwijsinspanning. Voor de organisatie van programma-onderdelen (planning, inroostering en onderwijsruimte) en technische ondersteuning (o.a. het opzetten van een E-portfolio en registratie van studieresultaten) krijgt de JSM ondersteuning vanuit het Onderwijsinstituut en de Graduate Schools.

\section{Landelijke initiatieven}

Binnen de Medische Wetenschappen in Nederland ontplooien een aantal faculteiten 'vergelijkbare' Honoursinitiatieven. Zo loopt binnen het Academisch Medisch Centrum/Universiteit van Amsterdam het 'Honoursprogramma Geneeskunde'. Studenten kunnen zich aan het eind van het eerste studiejaar aanmelden als zij voor alle tentamens in één keer geslaagd zijn en gemiddeld een 7.0 hebben gehaald. ${ }^{4}$ Het programma (36 ECs) bestaat uit extra vakken, parallel aan het reguliere bachelorprogramma van het tweede en derde studiejaar (bron: mevr. L. Olde Nordkamp, Honoursprogramma Geneeskunde AMC/UvA).

Binnen de Vrije Universiteit Medisch Centrum Amsterdam loopt sinds januari 2007 een Honoursprogramma (voorheen de 'masterclass') voor studenten geneeskunde. Studenten, die in december van het tweede studiejaar minimaal 7,5 of hoger of 'cum laude' hebben gehaald, worden door de faculteit uitgenodigd deel te nemen. Zij starten vervolgens in januari van het tweede studiejaar met een zogenaamde 'snuffelstage' bij een onderzoeksafdeling en schrijven in juni een onderzoeksvoorstel. In het derde studiejaar wordt het project uitgevoerd en afgesloten met een manuscript bestemd voor een 'peer-reviewed' tijdschrift. Studenten die het programma succesvol afronden ontvangen een certificaat (bron: dr. A.A. van Lambalgen, voorzitter Commissie Honours Programma VUmc).

Het Leids Universitair Medisch Centrum kent meerdere trajecten voor excellente studenten. ${ }^{5}$ Zo zijn er het 'Excellente Studententraject' (onderzoeksbeurs, max. 10 studenten), de pre-master Biomedische Wetenschappen (30 EC, max. 15 studenten), en de 'Honours Class' (12 bijeenkomsten, max. 15 studenten). Toelating is afhankelijk van studieresultaten, motivatie en wetenschappelijke belangstelling.

De Universiteit van Maastricht kent op dit moment één 'Honours Programma Geneeskunde', het 'Deelprogramma Wetenschappelijk Onderzoek ${ }^{6}{ }^{6}$ Dit aanvullende programma, bestemd voor de beste en meest gemotiveerde studenten geneeskunde (max. 20), start in het tweede studiejaar van de bachelorfase en loopt door in de masterfase. Selectie vindt plaats op basis van studieresultaten, motivatie en wetenschappelijke belangstelling. Aan het eind ontvangt de student een 'Honours Programma'-certificaat.

De Universiteit Utrecht is op dit moment bezig met de ontwikkeling van een Honoursprogramma (Honours CRU2006). In studiejaar 2007/2008 moet dit programma starten. ${ }^{7}$ De opleiding geneeskunde in Utrecht kent ook een $\mathrm{MD} / \mathrm{PhDtraject}$. Per jaar zijn er vijf stipendia beschikbaar. $^{8}$

De faculteiten Geneeskunde van de Radboud Universiteit Nijmegen en Erasmus Universiteit Rotterdam hebben geen specifieke Honours programma's voor studenten geneeskunde. Wel zijn er universiteitsbrede Honours Programma's. ${ }^{9-10}$

Een algemeen kenmerk van de 'Honours'- initiatieven is dat zij zich richten op de excellente, gemotiveerde studenten. De programma's zijn gericht op verdieping van de studie, meestal op het vlak van medisch-wetenschappelijk onderzoek, kennen een beperkt aantal plaatsen, een selectieprocedure (op basis van studieresultaten, motivatie en/of een gesprek) en starten meestal in het tweede studiejaar van de bachelorfase.

\section{JSM Groningen}

Het JSM Bachelor 'Honours'-traject onderscheidt zich duidelijk van de andere 'Honours'-initiatieven, al was het alleen maar door de grootschaligheid en jarenlang opgebouwde ervaring. Elke enthousiaste, gemotiveerde student geneeskunde kan vanaf de start van het eerste studiejaar (B1) deelnemen aan het traject zonder dat vooraf selectie plaatsvindt; selectie vindt alleen plaats voor Dé Cursusweek, en indien voor andere onderdelen een beperkt aantal plaatsen beschikbaar is. De indruk bestaat dat met dit - in opzet laagdrempelige - concept grotere aantallen studenten worden geënthousiasmeerd, zonder dat dit afbreuk doet aan het niveau. Studenten doorlopen bovendien niet allemaal hetzelfde traject, maar kunnen een individueel, op de belangstelling afgestemd, programma samenstellen. Met betrekking tot het $\mathrm{MD} / \mathrm{PhD}$-traject neemt het UMCG in Nederland een unieke positie in. Momenteel zijn 63 studenten actief binnen het $\mathrm{MD} / \mathrm{PhD}$-programma en hebben al 14 studenten het traject succesvol afgesloten. In 2006 zijn 22 projectvoorstellen gehonoreerd. De verwachting is dat ook in 2007 een vergelijkbaar aantal nieuwe projectvoorstellen zal worden toegekend.

Blijft de vraag of selectie noodzakelijk of wenselijk is. Eerste, voorlopige analyses laten zien dat studenten die deelnemen aan het JSM-programma, gemiddeld iets hoger scoren op eindexamencijfers (middelbare school) ten opzichte van de controlegroep. Wanneer echter globaal gekeken wordt naar studieresultaten (Voortgangstoetsen) in studiejaar B1 en B2 is geen onderscheid in 
studieprestaties waarneembaar. Een kwart van de MD/ $\mathrm{PhD}$-ers is in de bachelorfase nooit actief geweest binnen de JSM. Toch weten deze studenten voldoende voorwerk te verrichten om succesvol een $\mathrm{MD} / \mathrm{PhD}$-traject aan te kunnen vragen. Dit versterkt de JSM in haar mening niet bij aanvang van het programma te willen selecteren, om zodoende studenten volop de kans te bieden zich gedurende de eerste studiejaren te bewijzen en te bekwamen op het wetenschappelijke vlak.

JSM-studenten zijn wetenschappelijk succesvol. Zij publiceren meer wetenschappelijke artikelen dan reguliere studenten. Een cohort JSM-ers ( $\mathrm{n}=184$, aanvang studie 1997-2003) publiceerde tussen 1999-2006 284 PubMed-artikelen, 161 als eerste en 123 als co-auteur. Collega- studenten $(n=184$, gematched op aanvang studie, leeftijd en geslacht) wisten in dezelfde periode 'slechts' 47 artikelen te publiceren, 19 als eerste en 28 als co-auteur.

De JSM heeft zich als doel gesteld een professionele kweekvijver te zijn voor aanstaande clinici, die later patiëntenzorg willen combineren met wetenschappelijk onderzoek. Het is na acht jaar nog te vroeg om vast te stellen of de JSM deze doelstelling ook waar kan maken. De eerste indrukken zijn echter veelbelovend. Onderzoek in de komende jaren, gericht op de uitstroom van studentcohorten, moet antwoord geven op de vraag of het JSMprogramma daadwerkelijk effectief is.

\section{Een vooruitblik...}

Het aantal promoties binnen het UMCG heeft de afgelopen jaren een duidelijk stijgende lijn laten zien en de $\mathrm{MD} / \mathrm{PhD}$-ers, die de komende jaren gaan promoveren, zullen deze trend ondersteunen. Invoering van het MD/ $\mathrm{PhD}$-traject en vroeg promoveren bieden echter geen garanties dat de opgeleide (tand)artsen ook in het vervolg van hun carrière wetenschappelijke actief blijven. De meesten van deze gepromoveerde artsen starten met een 5-6 jarige specialisatie, gedurende welke periode zij de grip op wetenschappelijk onderzoek wel eens zouden kunnen verliezen. Het is evident dat dit speciale talent gekoesterd en gestimuleerd moet worden. Het UMCG is op dit moment dan ook bezig met de ontwikkeling van een nieuw opleidingsprogramma (post-doc stipendium) voor succesvolle $\mathrm{MD} / \mathrm{PhDers}$ en jong gepromoveerde artsen. Kenmerk van dit programma is dat de medische specialisatie wordt gecombineerd met periodes van wetenschappelijk onderzoek (als postdoc). Ter verdere scholing (tot toekomstig academisch specialist) dient tenminste één jaar van de onderzoeksperiode in het buitenland doorgebracht te worden, tenzij dit al plaats heeft gevonden tijdens de $\mathrm{MD} / \mathrm{PhD}$-periode. Met invoering van dit nieuwe postdoc stipendium voegt het UMCG een nieuwe pijler toe aan een versneld op de praktijk geënt opleidingsprogramma tot academisch arts/ specialist.

\section{Dankwoord}

De auteurs danken de leden van de programmagroep JSM, te weten dr. ing. J.R. Huizenga, mw. I.J.F. Engelhardt, dr. M.C. Harmsen, prof. dr. H.H. Kampinga, prof. dr. R.J. Porte, dr. W.J. van Son en prof. dr. H.J. Verkade, en mw. dr. C.S.M. Wachters- Kaufmann en prof. dr. T.H. The voor hun initiatieven en inzet bij de totstandkoming van het onderwijsprogramma van de Junior Scientific Masterclass.

Belangenconflict: geen gemeld.

Financiële ondersteuning: geen gemeld.

\section{Summary}

The Junior Scientific Master Class (JSM) offers highly motivated medical and dental students opportunities for participating and training in scientific research during their undergraduate studies. This programme enables students to obtain an honours degree in research during the Bachelor phase. They can also combine clerkships with a PhD project leading to a combined MD and PhD at the end the Master phase. University Medical Center Groningen aims to train more medical doctors and dentists with an interest in academic medicine in addition to clinical medicine. The honours programme offers additional training in basic scientific skills. It offers a range of courses and activities, including participation in a scientific pilot project. The honours programme adds 30 credits (European Credit Transfer System) to the 180 credits of the regular programme and the honours degree is indicated on the Bachelor certificate.

The combined MD/PhD programme offers students the opportunity to combine their Master phase with a $\mathrm{PhD}$ project and offers funding for two additional years of scientific research after the regular MD programme. This article gives an overview of the achievements of the first eight years of the JSM program and the start of a new educational honours programme. (Hooiveld MHW, Kluin-Nelemans JC. The Groningen Junior Scientific Master Class: a breeding ground for medical researchers. Dutch Journal of Medical Education 2007;26(6):288-296.)

\section{Literatuur}

Vandenbroucke JP. Financiering van medisch wetenschappelijk onderzoek in Nederland: nu gaan zorgen voor de toekomst. Ned Tijdschr Geneeskd 2002;146:1348-52.

Foekema H. Donkere wolken voor medisch wetenschappelijk onderzoek. Amsterdam: TNS NIPO; 2004.

Stukart MJ, Strijbosch MPW, Hooiveld MHW, Rees-Wortelboer MM van, Vandenbroucke JP, Klasen EC. Artsen en wetenschappelijk onderzoek: lichte teruggang van het aantal gepromoveerde artsen. Ned Tijdschr Geneeskd 2006;150:1509-12.

Beschikbaar op: www.amc.uva.nl/index.cfm?pid = 1275 [geciteerd op 14-9-07].

Beschikbaar op: www.lumc.nl/5050/speciaal.html [geciteerd op 149-07]. 
Beschikbaar op: www.unimaas.nl// [geciteerd op 14-9-07].

Beschikbaar op: www.umcutrecht.nl/subsite/Geneeskunde-CRU2006/Algemeen/Honours-CRU2006.htm [geciteerd op 149-07].

Beschikbaar op: www.umcutrecht.nl/subsite/opleidinggnk/ Studie-Informatie/MDPhD-traject.htm [geciteerd op 14-9-07].
Beschikbaar op: www.ru.nl/honoursprogramma [geciteerd op 149-07].

Beschikbaar op: www.eur.nl/onderwijs/opleidingen/honours [geciteerd op 14-9-07]. 